\title{
INFLUENCE OF THE TWO-ELECTRON TRANSITIONS ON THE RADIATIVE LIFETIMES OF EXCITED LEVELS IN Be ISOELECTRONIC SEQUENCE
}

\author{
P. Bogdanovich and R. Karpuškienè \\ Institute of Theoretical Physics and Astronomy of Vilnius University, A. Goštauto 12, LT-01108 Vilnius, Lithuania \\ E-mail: karra@itpa.lt
}

Received 19 October 2005

\begin{abstract}
The ions of beryllium isoelectronic sequence $(6 \leq Z \leq 30)$ are investigated using configuration interaction on the basis of transformed radial orbitals with a variable parameter. The energy spectra and radiative lifetimes of the levels of configurations $2 s^{2}, 2 s 2 p, 2 p^{2}, 2 s 3 l$, and $2 p 3 l$ are obtained. The aim of the present work is the investigation of the influence of the twoelectron transitions. It is shown that the two-electron transitions are decisive for the lifetimes of a few excited levels. The dependence of this influence on $Z$ is discussed.
\end{abstract}

Keywords: beryllium isoelectronic sequence, radiative lifetimes, two-electron transitions

PACS: 31.15.Ar, 31.25.Eb, 31.25.Jf

\section{Introduction}

During the last few years we have performed several investigations of highly charged ions with filling $2 p^{N}$ shell [1-6]. Theoretical calculations show that the excited configurations $2 s^{2} 2 p^{N-1} 3 p$ have two equally important decay channels. One of these is the ordinary one-electron transition to the configuration $2 s^{2} 2 p^{N-1} 3 s$, and such a type of transitions is registered and studied experimentally. The two-electron transitions to the configuration $2 s 2 p^{N+1}$ are regarded as the second decay channel of $2 s^{2} 2 p^{N-1} 3 p$. Although usually these transitions are not observed experimentally and are forbidden in single-configuration approach, they are possible. The methods based on the configuration interaction allow us to obtain the reliable probabilities of the two-electron transitions and to get the accurate lifetimes of the levels of the configurations $2 s^{2} 2 p^{N-1} 3 p$.

Till now the influence of the two-electron transitions on the lifetimes was not studied in series. The dependence of the influence on $Z$, i. e. along the isoelectronic sequence, attracted our attention.

The present paper is the first step towards such investigation and we have chosen the beryllium isoelectronic sequence with the ground configuration $2 s^{2}$. In other isoelectronic sequences, i.e. when the ground configuration has a $2 p$ shell, from the excited configu- ration $2 s^{2} 2 p^{N-1} 3 p$ both the one-electron transitions to the $2 s^{2} 2 p^{N-1} 3 s$ and the two-electron transitions to the $2 s 2 p^{N+1}$ are possible. The excited configuration $2 s 3 p$ of Be-like ions does not have the open $2 p$ shell and consequently there are three types of possible downward transitions: the two-electron transitions to the $2 p^{2}$ as well as the ordinary one-electron transitions to the $2 s 3 \mathrm{~s}$ and to the ground configuration $2 s^{2}$. The availability of the two types of one-electron transitions in beryllium isoelectronic sequence makes the influence of the twoelectron transitions quite different.

The ground configuration $2 s^{2}$ and the excited configurations $2 s 2 p, 2 p^{2}, 2 s 3 l$, and $2 p 3 l$ are studied. The obtained energy spectra and transition probabilities are used to calculate the radiative lifetimes in two ways. The values of total lifetimes include the probabilities of the one-electron and the two-electron transitions. Other values are calculated only with the probabilities of the one-electron transitions. The influence of the two-electron transitions is determined as a ratio of these two lifetime values, which is marked in the figures as $R$.

The short description of the calculation method is presented in the next section; the obtained results are discussed in Section 3. 


\section{Calculation}

The theoretical investigation of Be-like ions is performed using the method fully described and successfully applied in our previous papers [5-7]. While calculating the energy spectra, the relativistic effects were taken into account within the conventional Breit-Pauli approximation.

The correlation corrections were taken into account by the configuration interaction $(\mathrm{CI})$ technique. The basis set of non-relativistic radial orbitals was constructed as follows. The radial orbitals for electrons with $n \leq 3$ were determined by solving the Hartree-Fock equations [8]. For describing the excitations into the virtual states with a higher principal quantum number the transformed radial orbitals (TROs) with a variable parameter [9] were employed. The experience of their application to different atoms and ions (see Refs. [17]) has shown that such radial orbitals enable one to take into account the correlation corrections within the CI method quite efficiently. We obtain more accurate results because we study all configurations of the odd parity (or those of the even parity) simultaneously; in fact, the levels of these configurations are located comparatively close and the improvement of the levels of one configuration has an influence on the locations of the levels of configurations with the same parity. We must note that such an approach is very important for the calculation of the oscillator strengths and transition probabilities of the forbidden one-electron transitions, as well as for the determination of characteristics of the two-electron transitions.

TROs with $4 \leq n \leq 10$ and $l \leq 7$ are used in the energy spectra calculations. It is easy to get a large basis set of radial orbitals obtained by the method described in [9] and to generate many admixed configurations by virtual excitation of one or two electrons from $2 l$ and $3 l$ shells, but then the rank of the energy operator matrix becomes very large, too. It is necessary to reduce the number of the admixed configurations, because an account of such a number of the admixed configurations exceeds the possibilities of our personal computer. In this calculation the admixed configurations were selected according to their contribution to the wavefunction of the adjusted configurations. These contributions were evaluated in the second order of perturbation theory as described in papers $[10,11]$. These methods are based on the use of the second order of perturbation theory and the analytical expressions of the sums of squares of the interconfiguration matrix elements, together with the averaged energy differences between the adjusted and admixed configurations. They provide the balance of the accounted correlation corrections when the same selection criteria are used for each configuration. All configurations with the averaged weights higher than $10^{-9}$ are included into the set of admixed configurations. As it is shown in [12], such selection criterion is sufficient for the accurate calculations. The selection of the admixed configurations is performed using the program SELECTCONF [13].

The total number of the configuration state functions (CSFs) for each configuration of a given parity was found to be very large. The reduction of this number was made in the way described in [14] and was used in our previous calculations. This method is implemented in the program ATOTERM [15]. This program is written in Fortran and enables one to generate CSFs from the list of admixed configurations, taking into account different constraints. Since the Be-like ions have two electrons in open shells, the restrictions are put on the final $L S$ momenta only. Such a reduction is sufficient to get the matrices for separate final $L S$ of the orders not exceeding 10000 . That allows us to include all significant admixed configurations into the configuration interaction.

The multiconfiguration wave functions obtained by diagonalizing the matrix of the energy operator were used to compute the matrix elements of the electron transition operator and, correspondingly, the oscillator strengths and probabilities of the electric dipole transitions. The electric dipole transitions were evaluated using the "length" form of the transition operator. In the computations, along with our own computer codes, we also employed the program [16] for calculating the angular parts of the energy operator matrix elements and the programs $[17,18]$ for evaluating the characteristics of electronic transitions.

\section{Results and discussion}

The obtained energy spectra and radiative lifetimes of the excited levels were compared with the values obtained using the multiconfiguration Hartree-Fock method [19]. The comparison shows that our results contain more data on the energy levels and are in a good agreement with the data available from $[19,20]$.

Here we will analyse only one excited configuration $2 s 3 p$, because the influence of the two-electron transitions on the lifetimes of levels of other excited configurations either has similar dependence on $Z$ or is insignificant. The two-electron transitions from some excited levels are not possible at all. 


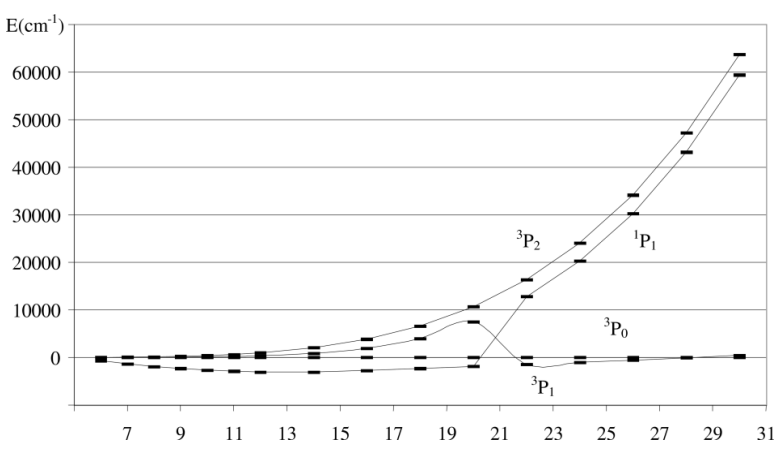

Fig. 1. Energies of $2 s 3 p^{3} \mathrm{P}_{1,2}$ and ${ }^{1} \mathrm{P}_{1}$ relative to $2 s 3 p{ }^{3} \mathrm{P}_{0}$.

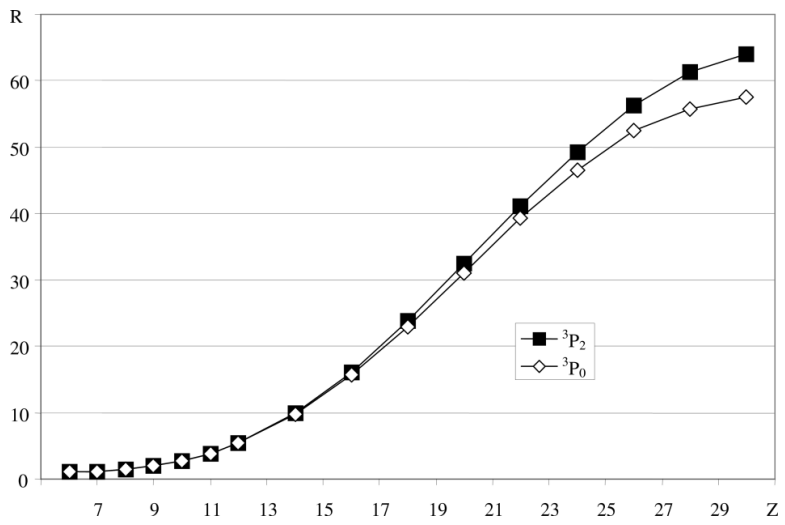

Fig. 2. Influence of the two-electron transitions on the lifetimes of $2 s 3 p{ }^{3} \mathrm{P}_{0}$ and $2 s 3 p{ }^{3} \mathrm{P}_{2}$.

Figure 1 presents the energy of levels $2 s 3 p^{1} \mathrm{P}_{1}, 2 s 3 p$ ${ }^{3} \mathrm{P}_{1,2}$ relative to energy of $2 s 3 p{ }^{3} \mathrm{P}_{0}$. As it is seen from Fig. 1 the singlet and triplet turn into two duplets when $Z>20$. The interchange of levels ${ }^{1} \mathrm{P}_{1}$ and ${ }^{3} \mathrm{P}_{1}$ at $Z=21$ is nonessential, because the denomination of levels is quite irrelevant, as the $L S$ coupling is not pure. Although the $j j$ coupling seems to be more usable here, the conventional Breit-Pauli approximation describes the ions with the ionisation degree up to 20 and more quite accurately and properly (e. g. see [21]).

The two-electron transitions have the largest influence on the lifetimes of levels ${ }^{3} \mathrm{P}_{0}$ and ${ }^{3} \mathrm{P}_{2}$ of the configuration $2 s 3 p$. As mentioned in the Introduction, the influence is determined as the ratio of total lifetime $\tau_{t}$ of an excited level and the lifetime $\tau_{1-\mathrm{el}}$ obtained with only the one-electron transition probabilities taken into account:

$$
R=\frac{\tau_{1-\mathrm{el}}}{\tau_{\mathrm{t}}} .
$$

The dependence of the influence on $Z$ is presented in Fig. 2. From this figure it is seen that the total lifetime $\tau_{\mathrm{t}}$ is dozens of times smaller than $\tau_{1-\mathrm{el}}$. The reasons of this are clarified in Fig. 3, where the probabilities of the strongest transitions from the $2 s 3 p{ }^{3} \mathrm{P}_{0}$ are presented. The probability of the two-electron transition to

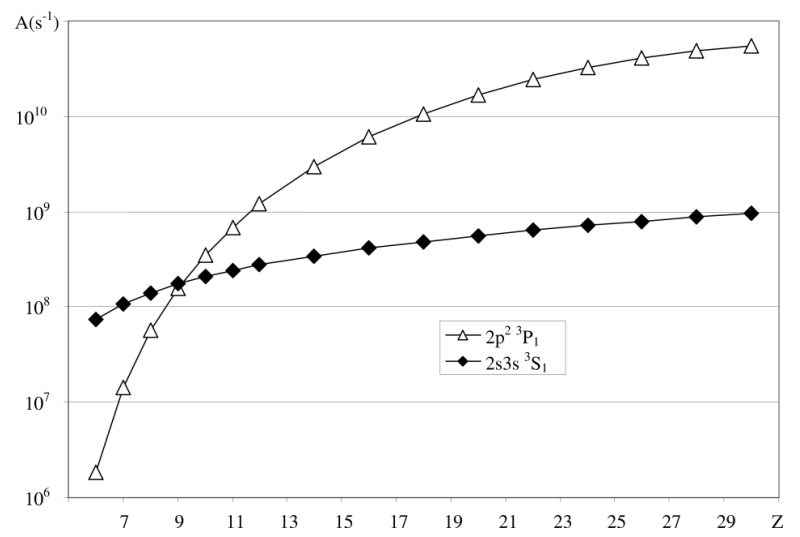

Fig. 3. The most probable transitions from the $2 s 3 p{ }^{3} \mathrm{P}_{0}$ to the indicated levels.

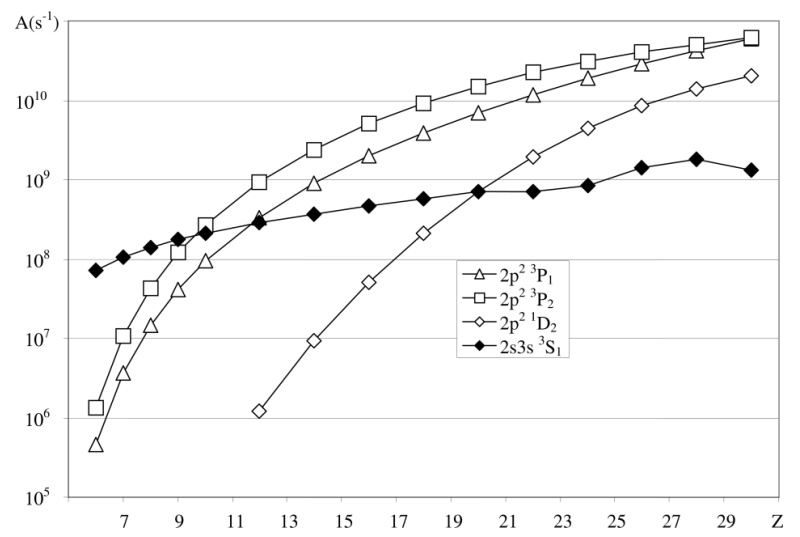

Fig. 4. The most probable transitions from the $2 s 3 p{ }^{3} \mathrm{P}_{2}$ to the indicated levels.

the $2 s 3 s{ }^{3} \mathrm{~S}_{1}$ depends on $Z$ very slightly, whereas the probability of the two-electron transition to the $2 p^{2}{ }^{3} \mathrm{P}_{1}$ increases along the isoelectronic sequence by a few orders. Namely, this causes the change of the lifetime of ${ }^{3} \mathrm{P}_{0}$. Other transitions from the level ${ }^{3} \mathrm{P}_{0}$ are the intercombination ones, and therefore they are weak or forbidden, because from this level only the transitions to the levels with $J=1$ are permitted by a selection rule.

The influence of the two-electron transitions on the lifetime of ${ }^{3} \mathrm{P}_{2}$ is similar, because the strongest transitions from this level depend on $Z$ in a similar manner as the transitions from ${ }^{3} \mathrm{P}_{0}$ (Fig. 4). From the level ${ }^{3} \mathrm{P}_{2}$ a few strong two-electron transitions are possible, unlike from the ${ }^{3} \mathrm{P}_{0}$. That happens because the selection rule $\Delta J=0, \pm 1$ permits two transitions to the $2 p^{2}{ }^{3} \mathrm{P}_{1,2}$ as well as an intercombination one to the $2 p^{2}{ }^{1} \mathrm{D}_{2}$, which has not so large probability, but further it exceeds the probability of the one-electron transition to $2 s 3 s$ when $Z>20$.

The influence of the two-electron transitions on the lifetime of the $2 s 3 p{ }^{3} \mathrm{P}_{1}$ is also not large, but its dependence on $Z$ is non-monotonic (Fig. 5). There are 


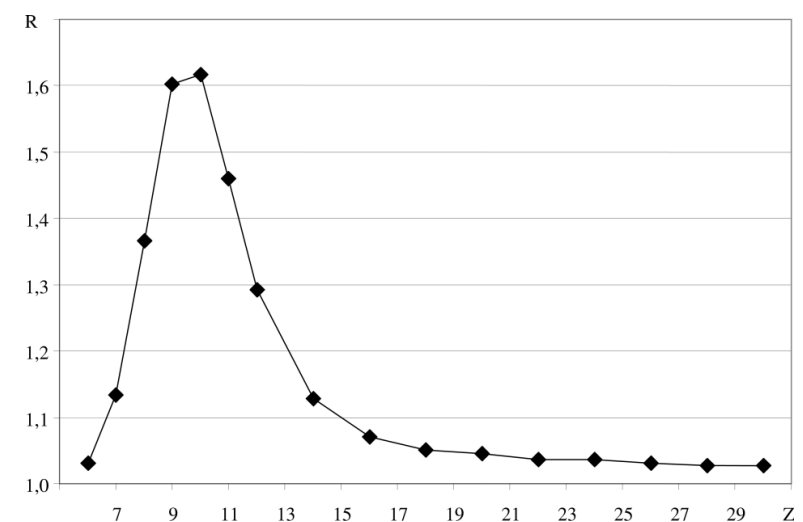

Fig. 5. The influence of the two-electron transitions on the lifetimes of $2 s 3 p{ }^{3} \mathrm{P}_{1}$

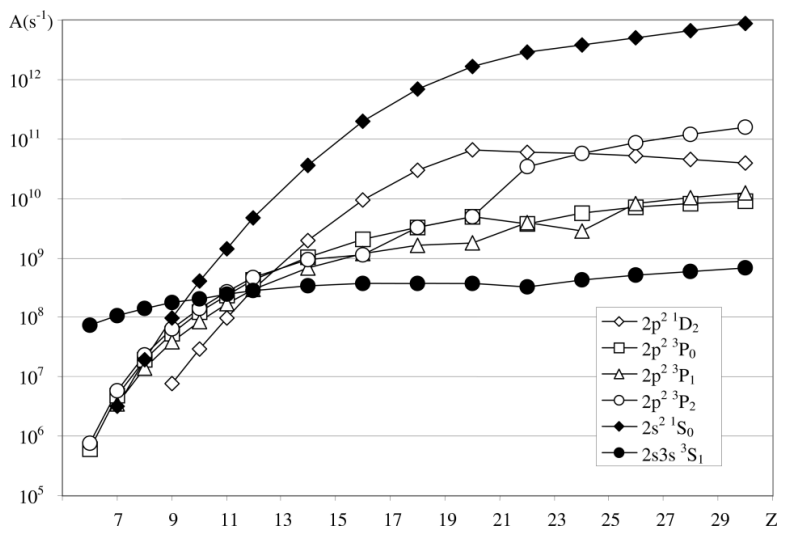

Fig. 6. The most probable transitions from the $2 s 3 p{ }^{3} \mathrm{P}_{1}$ to the indicated levels.

a few strong transitions of both types from this level (Fig. 6). The probabilities of the two-electron transitions increase along the isoelectronic sequence in a similar way, consequently, their influence must also increase. The dependences of probabilities of two possible one-electron transitions on $Z$ are entirely different, because of different final configurations. While $Z$ are small, the probability of the intercombination transition to the $2 s^{2}{ }^{1} \mathrm{~S}_{0}$ is insignificant in comparison with the probability of the one-electron transition to the $2 s 3 s$ ${ }^{3} \mathrm{~S}_{1}$ and the two-electron transitions. With a growth of $Z$ the probability of $2 s 3 p{ }^{3} \mathrm{P}_{1}-2 s 3 s{ }^{3} \mathrm{~S}_{1}$ transitions increases very slightly and generally it is smaller than the probabilities of the two-electron transitions. The probability of intercombination transition to the $2 s^{2}$ ${ }^{1} \mathrm{~S}_{0}$ increases rapidly and it exceeds the strongest twoelectron transitions significantly when $Z>12$. That is the reason why the influence of the two-electron transitions grows at the beginning of the isoelectronic sequence, then goes down, and becomes negligible when the probability of the intercombination one-electron

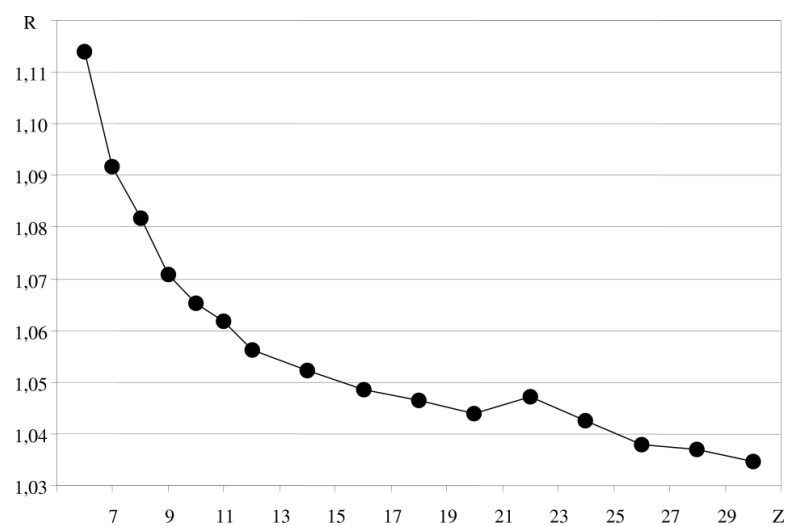

Fig. 7. The influence of the two-electron transitions on the lifetimes of $2 s 3 p{ }^{1} \mathrm{P}_{1}$.

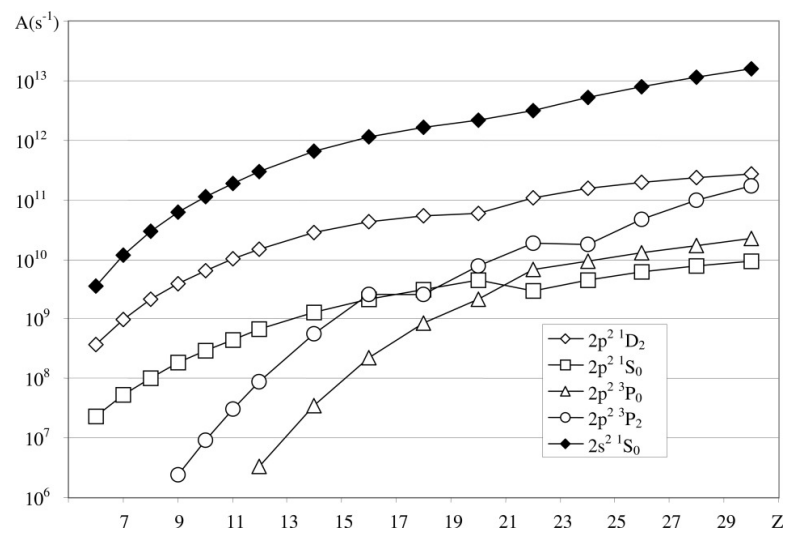

Fig. 8. The most probable transitions from the $2 s 3 p{ }^{1} \mathrm{P}_{1}$ to the indicated levels.

transition $2 s 3 p^{3} \mathrm{P}_{1}-2 s^{2}{ }^{1} \mathrm{~S}_{0}$ significantly exceeds the probabilities of the other ones.

For the lifetimes of $2 s 3 p{ }^{1} \mathrm{P}_{1}$ the influence of the two-electron transitions is not so significant and, differently, it decreases along the isoelectronic sequence (Fig. 7). The probabilities of the strongest transitions from this level are presented in Fig. 8. The one-electron transition to the $2 s^{2}{ }^{1} \mathrm{~S}_{0}$ is decisive here. The probability of this transition is larger by one order or more than the probabilities of the two-electron transitions along the whole isoelectronic sequence.

\section{Conclusions}

Our calculations and performed investigations show that in the beryllium isoelectronic sequence the influence of the two-electron transitions on the lifetimes depends on the ionisation degree. When $Z$ is greater than 12 , i.e. the ionisation degree is high enough, the probabilities of the one-electron transitions without the principal quantum number change $2 s 3 p-2 s 3 s$ are smaller than the probabilities of transitions with 
$\Delta n=1:$ the one-electron $2 s 3 p-2 s^{2}$ and the twoelectron $2 s 3 p-2 p^{2}$ ones. So, the ordinary one-electron transition $2 s 3 p-2 s 3 s$ is not so important for the determination of lifetimes of excited levels of the $2 s 3 p$ in highly charged Be-like ions. The influence of the two-electron transitions $2 s 3 p-2 p^{2}$ is huge when the one-electron transitions to the $2 s^{2}$ are forbidden by the selection rules, i. e. for the excited levels $2 s 3 p^{3} \mathrm{P}_{0,2}$. If the intercombination transition $2 s 3 p-2 s^{2}$ is permitted, the influence of the two-electron transitions is insignificant, similarly as for the levels $2 s 3 p^{3} \mathrm{P}_{1}$ and ${ }^{1} \mathrm{P}_{1}$.

\section{References}

[1] P. Bogdanovich, R. Karpuškienė, and I. Martinson, Ab initio wavelengths and oscillator strengths for $\mathrm{Cl} \mathrm{X}$, Phys. Scripta 67, 44-51 (2003).

[2] P. Bogdanovich, R. Karpuškienè, and I. Martinson, Theoretical lifetimes of excited $\mathrm{Cl} \mathrm{X}$ configurations, Nucl. Instrum. Methods B 205, 70-73 (2003).

[3] P. Bogdanovich, R. Karpuškienè, and A. Udris, Theoretical study of the energy spectrum of the $2 p^{3} 3 p$ in S IX and related electron transitions, Phys. Scripta 67, 395-400 (2003).

[4] R. Karpuškienè and P. Bogdanovich, Two-electron transitions and their importance for lifetimes of levels of configuration $2 p^{4} 3 p$ in K XI, J. Phys. B 36, 21452152 (2003).

[5] P. Bogdanovich and R. Karpuškienè, The theoretical study of spectral characteristics of Ar X, Nucl. Instrum. Methods B 235, 174-179 (2005).

[6] R. Karpuškienè, P. Bogdanovich, and A. Udris, Ab initio oscillator strengths and transition probabilities of transitions from $2 s^{2} 2 p^{2} 3 l$ and $2 s 2 p^{3} 3 l$ in $\mathrm{S} \mathrm{X}$, At. Data Nucl. Data Tables 89, 45-76 (2005).

[7] P. Bogdanovich and R. Karpuškienè, The theoretical study of the overlapping configurations $2 s 2 p^{5} 3 l$ and $2 s^{2} 2 p^{4} 4 l$ in Ar X, J. Phys. B 38, 1557-1568 (2005).

[8] C. Froese Fischer, A general Hartree-Fock program, Comput. Phys. Commun. 43, 355-363 (1987).

[9] P. Bogdanovich and R. Karpuškienè, Transformed radial orbitals with a variable parameter for the configuration interaction, Lithuanian. J. Phys. 39, 193-208 (1999).
[10] R. Karpuškienė, R. Karazija, and P. Bogdanovich, The averaged energy distance between two interacting configurations and its application for the investigation of CI in atoms, Phys. Scripta 64, 333-347 (2001).

[11] P. Bogdanovich and R. Karpuškienè, Numerical methods of the preliminary evaluation of the role of admixed configurations in atomic calculations, Comput. Phys. Commun. 134, 321-334 (2001).

[12] P. Bogdanovich, Modern methods of multiconfiguration studies of many-electron highly charged ions, Nucl. Instrum. Methods B 235, 92-99 (2005).

[13] P. Bogdanovich, R. Karpuškienè, and A. Momkauskaite, A program of generation and selection of configurations for the configuration interaction method in atomic calculations SELETCONF, Comput. Phys. Commun. 172, 133-134 (2005).

[14] P. Bogdanovich, R. Karpuškiene, and A. Momkauskaite, Some problems of calculation of energy spectra of complex atomic configurations, Comput. Phys. Commun. 143, 174-180 (2002).

[15] P. Bogdanovich and A. Momkauskaite, A program for generating configuration state lists in manyelectron atoms, Comput. Phys. Commun. 157, 217225, (2004).

[16] G. Gaigalas, The library subroutines for calculation of matrix elements of two-particle operators for manyelectron atoms, Lithuanian J. Phys. 42, 73-86 (2002).

[17] C. Froese Fischer, M.R. Godefroid, and A. Hibbert, A program for performing angular integrations for transitions operators, Comput. Phys. Commun. 64, 486-500 (1991).

[18] C. Froese Fischer and M.R. Godefroid, Programs for computing LS and LSJ transitions from MCHF wavefunctions, Comput. Phys. Commun. 64, 501-519 (1991).

[19] C. Froese Fischer and G. Tachiev, Breit-Pauli energy levels, lifetimes, and transition probabilities for the beryllium-like to neon-like sequences, At. Data Nucl. Data Tables 87, 1-184 (2004).

[20] http: / / atoms.vuse.vanderbilt.edu/

[21] V. Jonauskas, P. Bogdanovich, F.P. Keenan, M.E. Foord, R.F. Heeter, S.J. Rose, G.J. Ferland, R. Kisielius, P.A.M. van Hoof, and P.H. Norrington, Energy levels and transition probabilities for nitrogen-like Fe XX. Astron. and Astrophys. 433(2), 745-750 (2005). 


\title{
DVIELEKTRONIŲ ŠUOLIŲ ITAKA BERILIO IZOELEKTRONINĖS SEKOS JONŲ SUŽADINTŲ LYGMENŲ GYVAVIMO TRUKMĖMS
}

\author{
P. Bogdanovičius, R. Karpuškienè
}

VU Teorinès fizikos ir astronomijos institutas, Vilnius, Lietuva

\section{Santrauka}

Naudojant konfigūracijų superpozicijos metodą, transformuotų radialiųju orbitalių su varijuojamu parametru bazeje ištirti berilio izoelektroninès sekos jonai $(6 \leq Z \leq 30)$, gauti konfigūraciju $2 s^{2}, 2 s 2 p, 2 p^{2}, 2 s 3 l$ ir $2 p 3 l$ energijos spektrai ir lygmenu gyvavimo trukmès. Išnagrinèta dvielektroniu šuoliu įtakos priklauso- mybė nuo $Z$. Gauti rezultatai parodè, kad stipriai jonizuotiems atomams konfigūracijos $2 s 3 p$ lygmenų gyvavimo trukmėms reikšmingiausi yra ne iprasti vienelektroniai šuoliai i konfigūraciją $2 s 3 s$. Lygmenu $2 s 3 p{ }^{3} \mathrm{P}_{0,2}$ gyvavimo trukmes lemia dvielektroniai šuoliai ì konfigūraciją $2 p^{2}$, o lygmenu ${ }^{3} \mathrm{P}_{1}$ ir ${ }^{1} \mathrm{P}_{1}$ - vienelektroniai šuoliai i pagrindinę konfigūraciją $2 s^{2}$. 